\title{
HISTÓRIA, INSTITUIÇÕES, ARQUIVOS E FONTES NA PESQUISA E NA HISTÓRIA DA EDUCAÇÃ̃O
}

\author{
Paulino José Orso²
}

\section{RESUMO}

Este artigo, como o próprio título o indica, trata da relação entre a história, as instituições, os arquivos e as fontes na pesquisa e na história da educação. Discute acerca da importância de cada uma delas para que o homem possa se conhecer, se localizar no espaço e no tempo, bem como, agir sobre o meio. Para isso, chama atenção sobre a relevância tanto das fontes para o acesso ao passado, como da necessidade de preservar a memória por meio dos arquivos e das instituições, o que também pressupõe a exigência da utilização de um método adequado para que possamos apreender a realidade efetivamente como ela é e poder pensar e agir de forma intencional e deliberada, transformando o que se apresenta enquanto tendências decorrentes do passado.

Palavras-chave: história, educação, instituições escolares, arquivos, fontes, pesquisa educacional

\section{HISTORY, INSTITUTIONS, ARCHIVES AND SOURCES IN RESEARCH AND HISTORY OF EDUCATION}

\begin{abstract}
This article, as its title suggests, deals with the relationship between history, institutions, archives and sources in research and education history. Discusses about the importance of each one of them so that man can know each other, to locate in space and time, as well as act upon the environment. To do so, draws attention to the relevance of both the sources for access to the past, such as the need to preserve the memory through the archives and institutions, which also implies the requirement of using an appropriate method for us to grasp reality effectively as it is and be able to think and act intentionally and deliberately turning what is presented as arising from past trends.
\end{abstract}

Keywords: history education, educational institutions, files, fonts, educational research

A História da Educação se constitui numa disciplina um tanto recente e ainda carece de muita investigação e reflexão para dar conta de compreendê-la como efetivamente tem ocorrido e porque ela se realizou da forma como ocorreu. Esta é uma tarefa desafiadora, pois, como não poderia ser diferente, remete a investigar o passado e compreendê-la juntamente com a totalidade das demais relações. Trata-se de reconstituir a história pregressa, que é algo que não é possível acessar diretamente. Para fazê-lo necessita-se de mediações, de instrumentos e meios que possibilitem "retornar ao passado", às suas condições, relações e circunstâncias.

Muitas vezes, os pesquisadores tendem a supervalorizar a sua área de interesse, pesquisa e atuação, de tal modo que, ao invés de aparecer como realmente é, uma particularidade, acabam apresentando-as como se fossem absolutas. Neste sentido, é bom ressaltar que a história da educação não se confunde com a própria história, é apenas uma 
"parte", um "capítulo" da História Geral. Daí decorre um duplo desafio. Por um lado, o de recuperar a história da educação e, enquanto uma particularidade, entendê-la como expressão característica da universalidade e, por outro, o de, por intermédio da mesma, possibilitar a compreensão da história como um todo.

Conhecer a história é uma condição de fundamental importância para podermos compreender o movimento histórico, verificar como e de que forma fomos fazendo e percorrendo a história. Este conhecimento é condição sine qua non para pensarmos nas mudanças.

Porém, se hoje se pode dizer que estamos procurando resgatar a história do passado (com atraso), após tê-la vivido, num momento em que muitas de suas marcas e de suas fontes já foram perdidas, modificaram-se, ou até mesmo, terem sido intencionalmente destruídas, podemos nos antecipar e tomar algumas medidas para que isso não venha a se repetir no futuro. Neste momento, contraditoriamente, também podemos fazer uso dos meios científicos que já foram produzidos, que temos à nossa disposição para ajudar a preservar as fontes e a memória histórica ${ }^{3}$.

Neste sentido, o processo de resgate das fontes amplia as possibilidades de compreensão da História da Educação e da própria história, na medida em que se relacionam com a totalidade social de cada momento. Não há outro modo de recuperar e reconstruir a histórica senão por meio das fontes, quaisquer que sejam elas. $\mathrm{O}$ fato é que o acesso ao passado depende essencialmente delas, que são as bases para a produção historiográfica. Por isso, a importância de localizar, preservar e socializar essas fontes. Mas, para isso, é necessário lançar mão de um método adequado que permita chegar efetivamente a elas, caso contrário, podemos ficar apenas na superficialidade e pensarmos que isso é tudo. Da mesma forma, não podemos permanecer na aparência e pensar que isto é absoluto e independente, que está desprovido de relações e implicações. Daí a necessária seriedade do pesquisador para trazer à tona "a história como ela é".

Entretanto, este desafio não pode ficar restrito apenas a um pesquisador ou até mesmo a um grupo de pesquisadores, ao contrário, deve ser assumido por todos os educadores, escolas, gestores e autoridades ligadas à educação. Assim como é também necessário procurar integrar o ensino, a pesquisa e a extensão, além de se articular ao Ensino Fundamental, ao Médio e ao superior, no intuito de potencializar as possibilidades e garantir um melhor conhecimento da história da educação, principalmente da educação de cada região, desvelando aspectos desconhecidos por muitos pesquisadores até o momento.

Em função do tamanho desafio que se coloca para resgatar a história e a memória, é relevante estabelecer planos, organizar atividades sistemáticas de reflexão, promover a organização e o planejamento das ações a serem desencadeadas, organizar cursos, linhas de pesquisas e definir projetos e metas a serem atingidas. Com isso, ampliam-se as possibilidades de investigação e também de conhecimento, tanto da educação, da história local, como da história universal. Uma vez perseguidos estes caminhos, articulados ao um método adequado, as produções vão se somando, as lacunas vão sendo preenchidas, possibilitando o domínio da realidade, bem como, sua socialização.

Por mais esforços que se faça em torno do desafio proposto, percebe-se o limite de ação dos indivíduos e dos grupos isolados. Diante disso, torna-se necessário desenvolver um trabalho de sensibilização junto à comunidade, principalmente, secretarias municipais, núcleo regional de educação e escolas no sentido de despertarmos a preocupação com a catalogação, a sistematização, socialização e a preservação das fontes. Do contrário, por mais esforços que se fizesse, o trabalho ficaria limitado e comprometido. 
Neste sentido, há a necessidade do envolvimento das escolas e de seus profissionais no esforço de preservação da memória institucional da Escola Pública. É evidente que nem todas as ações humanas ficam registradas para a posteridade, pois, muitas acabam se perdendo no tempo e não podem mais ser recuperadas, descritas, memorizadas e contadas, o que, aliás, é próprio da perenidade e da transitividade da matéria.

Como afirma José Claudinei Lombardi, ao longo da história, nas suas ações e relações com a natureza e com os demais semelhantes, os "homens produziram (e ainda produzem) artefatos, documentos, testemunhos, monumentos entre outros, que tornam possível o entendimento do homem sobre sua própria trajetória" (2004, p. 155-6). Contudo, isto tudo tem um limite, o limite das condições e da etapa de desenvolvimento atingida em cada momento histórico.

Os registros históricos são os meios utilizados pelos historiadores para se apropriar de uma realidade que "já não existe" e produzir determinadas explicações históricas. Porém, a qualidade do conhecimento histórico que se produz depende da relação dos historiadores com as fontes. Assim, uma relação mais sólida com as fontes, só será possível, quando eles não mais necessitarem gastar grande parte do tempo de pesquisa para localizá-las, quando já estiverem organizadas e preservadas em arquivos. Sendo assim, ao localizar e catalogar as fontes investe-se na qualidade das pesquisas, do ensino e da extensão das futuras gerações.

Desta forma, o desafio consiste em criar as condições objetivas para a preservação das fontes, quer sejam elas, das Instituições Escolares, da sua organização, do seu funcionamento, que possibilitem ao historiador buscar a explicitação da singularidade e da identidade histórica dos fatos, das Instituições Escolares.

Com relação ao significado da reconstrução histórica das Instituições Escolares recorremos ao historiador Eric Hobsbawm, quando nos diz que: "O passado é, portanto, uma dimensão permanente da consciência humana, um componente inevitável das instituições, valores e outros padrões da sociedade humana". Ou ainda, "[...] o passado continua a ser a ferramenta analítica mais útil para lidar com a mudança constante, mas em uma nova forma" (1998, p. 22 e 30). Noutras palavras, pode-se afirmar que, voltar-se para o passado é a condição para construir um futuro com melhores condições. Dito de outro modo, deve-se avançar para o futuro, tendo o passado como uma espécie de "retrovisor", para definirmos as decisões, o rumo e a direção a tomar no caminho.

Vale ressaltar, que no trabalho de reconstrução histórica é importante a relação do pesquisador com as fontes, pois "a amplitude do olhar do pesquisador se dá ao levantar as fontes. Aí ele não identifica apenas objetos específicos, mas descobre outras questõessociais que demarcam um período (MIGUEL, 2004, p. 116).

Depois desta breve digressão que teve como objetivo situar de onde fazemos esta discussão, retornamos à temática objeto deste artigo, começando por reafirmar que a História da Educação é apenas uma parte da História, o processo de transformação operado pela e na educação, mas que na verdade, tem a ver com a totalidade social de cada momento. Contudo, ainda que assim o seja, não se pode desconsiderar que, em sendo parte, ou justamente por isso, por um lado, ela não é absoluta, nem está isolada no tempo e no espaço e, por outro, que está situada num contexto sócio-histórico, econômico e cultural, que tem a ver com a totalidade das relações sociais de uma determinada época e lugar.

Portanto, não existe uma história da educação no sentido estrito, como se ela estivesse à parte do conjunto da história geral. Só podemos falar de uma história da educação de uma forma didática, pois, na verdade temos uma única história, a história do 
homem, da sociedade, a história geral e, inerente a ela, uma de suas dimensões, que é a educação formal.

O fato é que frequentemente a isolamos daquela e tomamos esta como se fosse autônoma e independente. Por isso é que, frequentemente, vemos produções que, partindo de métodos questionáveis, afirmam tratar-se de "uma visão", "um olhar", que remetem apenas ao "indivíduo", à "subjetividade", ou a um "momento". Deste modo, criamos inúmeros problemas tanto para compreender a história da educação, como a própria sociedade, uma vez que isso não se compreende, nem se explica independente do conjunto das relações. Por isso, ao nos ocuparmos da educação, não podemos desconsiderar ou desprezar a totalidade social.

Dito desta forma, portanto, também pode-se depreender o caráter histórico da educação. Mas, o que significa dizer que a educação possui um caráter histórico? Significa dizer que ela não foi, não é, nem será sempre a mesma; significa afirmar que em cada momento, época e sociedade temos um determinado tipo de educação, aquela que corresponde às condições e à etapa de desenvolvimento do momento. Por outro lado, também significa que "o momento presente não é apenas o momento presente", pois, carrega junto, de modo contraditório, porém, a totalidade das relações e condições que o antecederam.

É neste sentido que se pode falar que a educação é determinada, que não ocorre ao "acaso", de qualquer modo, nem de modo espontâneo e naturalmente. Aliás, o acaso não existe. Ao contrário, significa que ela não só é determinada, como multideterminada, ou seja, a modalidade, a qualidade, a quantidade, sua forma e conteúdo, sua extensão, não são produtos unilaterais de um determinante único. Diferente disso, são resultados de inúmeros fatores, uns conscientes, explícitos, claros, voluntários, mais ou menos visíveis, outros, ocultos e até camuflados. Deste modo, pode-se asseverar que a educação de cada momento aparece, manifesta-se e caracteriza-se como uma síntese das relações que a precederam.

Assim, como a educação é multideterminada, significa afirmar que, para compreendê-la em profundidade, é necessário recorrer a muitas fontes, que, cada uma delas, por sua vez, também é multideterminada.

A questão, portanto, que está colocada, é: como reconstruir a História da Educação, quer seja ela brasileira ou regional, considerando que ela é multideterminada? Porque, afinal de contas, é importante e necessário conhecer a história da educação? Não basta ir fazendo educação do jeito que aprendemos a fazer, de acordo com as experiências acumuladas? Comecemos por esta última questão. De fato não basta ir fazendo educação, de forma espontânea, sem refletir sobre a(s) teoria(s) e a(s) prática(s) que as embasam, como se o que fazemos e a forma como fazemos não acarretassem muitas e sérias implicações sociais. De acordo com Alvoro Vieira Pinto,

A pesquisa científica constitui um tema e cuja consideração o homem de ciência, em geral, e o pesquisador, em particular, não podem deixar de se dedicar. Qualquer que seja o campo de atividade a que o trabalhador científico se aplique, a reflexão sobre o trabalho que executa, os fundamentos existenciais, os suportes sociais e as finalidades culturais que o explicam, o exame dos problemas epistemológicos que a penetração no desconhecido mundo objetivo suscita, a determinação da origem, poder e limites da capacidade perscrutadora da consciência, e tantas outras questões deste gênero, que se referem ao processo da pesquisa científica e da lógica da ciência, não podem ficar à parte do campo de interesse do pesquisador, que precisa conhecer a natureza do 
seu trabalho, porque, [...], é constitutivo da sua própria realidade individual (1979, p. 3).

Aqui pode-se substituir pesquisador ou historiador por educador que dá no mesmo. Ou seja, é necessário que o educador reflita sobre a prática que realiza. Não pode dar-se por satisfeito em ir fazendo de qualquer modo, desprovido de quaisquer pressupostos, sob pena de provocar sérios problemas sociais. Neste sentido, se não se pode executar um trabalho sem a devida reflexão sobre o mesmo, também é insuficiente, fazê-lo com base apenas na experiência espontânea, acumulada ao longo dos anos. Assim, é preciso superar a

Posição metodológica que privilegiasse a tal ponto o hábito, a prática, o exercício profissional da pesquisa, que julgasse dispensável o apelo à reflexão teórica, a busca de princípios lógicos e de bases epistemológicas para construir a teoria da investigação, julgando que o simples fato de haver-se um sábio dedicado ao trabalho de descoberta, às vezes por uma vida inteira, valendo-se das inspirações do bom senso, seja suficiente para qualificá-lo a criar uma doutrina ou a pronunciar apreciações teóricas a respeito do problema geral da pesquisa científica (Idem, p. 5-6).

Essa insuficiência remete a que se faça um trabalho sério, reflexivo, consequente, em função das repercussões e consequências do trabalho que se faz. Para isso, é necessário que se realize o trabalho educacional a partir de uma perspectiva filosófica, que leve em conta os determinantes e os desencadeamentos sociais.

Mas, porque, afinal de contas, é importante e necessário conhecer a história da educação? Primeiro, porque o acesso à educação tornou-se uma condição indispensável para se viver na sociedade atual. E, em decorrência disso, também é necessário conhecer a história, seja ela da educação ou geral, uma vez que seu conhecimento é imprescindível para intervir nela e mudá-la.

O conhecimento é condição para transformação. Portanto, partindo do pressuposto de que precisamos transformar a educação, também é necessário conhecê-la. Mas, como fazer para conhecê-la de modo eficaz e efetivo? Daí o recurso às fontes é indispensável a partir de um método adequado. Assim é possível se chegar ao passado como ele "realmente" ocorreu, ao passado vivido. Não há outra forma de "reconstruir" a história senão deste modo.

Se, como dissemos acima, a história da educação no Brasil é muito recente, a pesquisa educacional brasileira o é ainda mais e pode ser marcada por três momentos. $\mathrm{O}$ primeiro, quando praticamente teve seu início, na década de 1950. O segundo, quando são criados os Programas de Pós-Graduação em Educação e a pesquisa adquire grande impulso, durante a ditadura militar, nas décadas de 1970 e 1980 . O terceiro, quando ocorre a consolidação da pós-graduação, a partir dos anos de 1990. Nesse momento, ocorre a chamada crise dos "paradigmas". Então, propõe-se

o pluralismo epistemológico e temático e privilegia-se o estudo de objetos singulares. [...] é representado pela ampliação das linhas de investigação, pela diversificação teórico-metodológica e pela utilização das mais variadas fontes de pesquisa. Mas, segundo alguns estudiosos, o que está havendo é, na verdade, uma fragmentação epistemológica e temática que dificulta a compreensão da totalidade do fenômeno educacional. Mais ainda, muitos deles vêem, nessa crise paradigmática, um largo movimento antimarxista e o abandono da perspectiva histórica.

Revista HISTEDBR On-line, Campinas, número especial, p. 228-238, mai2012 - ISSN: 1676-2584 232 
Nessa perspectiva, dizem, são privilegiados temas como cultura escolar, formação de professores, livros didáticos, disciplinas escolares, currículo, práticas educativas, questões de gênero, infância e, obviamente, as instituições escolares. A nova história, a história cultural, a nova sociologia, a sociologia francesa constituem as matrizes ou a tela de fundo teórica das pesquisas realizadas (http://www.faced.ufu.br/colubhe06/anais/arquivos/463PaoloNosell a_EsterBuffa.pdf). (consultado em 20.08.11).

$\mathrm{Na}$ esteira deste último movimento, nas últimas décadas tem-se feito muita pesquisa, escrito muitos artigos, livros e capítulos de livros tendo como objeto as fontes, os arquivos históricos e instituições escolares ${ }^{4}$. Contudo, a grande maioria deles tem sido feitas a partir de métodos que apenas permitem conhecimentos parciais e tem sofrido influência, dentre outros métodos ou concepções, da dita nova história e da chamada pósmodernidade, assim como tem se colocado francamente em oposição ao marxismo. Isto tem implicando numa análise um tanto restrita, estreita, focada, fixa, geralmente de caráter descritivo. Com efeito, dizem os autores,

este tipo de pesquisa apresenta sérios perigos metodológicos, porque o envolvimento do estudioso é fácil; [...] Frequentemente, o pesquisador resvala em reducionismos teóricos tais como particularismo, culturalismo ornamental, saudosismo, personalismo, descrição laudatória ou apologética. De fato, estudos e pesquisas que retratem, de forma curiosa, aspectos singulares da instituição escolar, em tempos diversos, são fascinantes e até sedutores. Quem não gosta de saber como eram vestidas e educadas as crianças dos séculos passados e suas brincadeiras ou como as normalistas representavam a relação diploma-casamento? Ou ainda, quem não gosta de ver enaltecidos os fundadores de uma escola significativa para sua própria cidade? Ou, finalmente, quem não gosta de ver, consagrados em livros, nomes e fotografias de seus antepassados? Estudos como estes agradam a inúmeros leitores. No entanto, por mais sedutoras que sejam essas pesquisas, não se pode admitir que a descrição pormenorizada de uma dada instituição escolar deixe de levar o leitor à compreensão da totalidade histórica. A dificuldade principal reside exatamente aí: conseguir evidenciar, de forma conveniente, o movimento real da sociedade, como insistem os marxistas (Idem).

Isto, ainda que tenha lá sua importância e dê alguma contribuição para a compreensão dos objetos e da história, o faz de uma forma bastante parcial, como se os objetos tivessem uma razão de ser em si e se circunscrevessem em si mesmos. Da mesma forma que não podemos entender os indivíduos por si mesmos, também não se pode entender as fontes por si, uma vez que são muitideterminadas.

Por isso, há a necessidade de, emblematicamente, superar três perspectivas teóricas. Por um lado, o positivismo, que toma as fontes como se fossem meros dados ou objetos postos aí, como se falassem por si mesmos. Como dizem Paulo Nosella e Ester Buffa

Para os positivistas, o dado empírico é um absoluto, um fim em si mesmo. Não se propõem eles nem o conhecimento, nem a mudança da sociedade como um todo. Assim, no estudo de uma instituição escolar, o pesquisador positivista se encanta com as fontes e acredita que os dados falam por si. Sua postura fundamental é descrever fielmente a maior parte de dados da Escola (Idem). 
Por outro, a fenomenologia e idealismo, concebem os objetos/as fontes como se fossem produtos da consciência do pesquisador; os objetos são objetos de e para a consciência. De acordo com os autores acima mencionados,

O idealismo, por sua vez, supervaloriza a subjetividade e a intencionalidade humanas. Essa tendência teórica considera que a ideia é o demiurgo da história. Desse ponto de vista, o pesquisador, ao retratar a história de uma instituição escolar, atribui o mérito principal da sua criação e sucesso, aos fundadores, ao pensamento dos grandes pedagogos e às atividades formativas daquela específica escola (idem).

Por outro lado ainda, temos o estruturalismo, que compreende a realidade, os objetos e a sociedade como se fossem meras estruturas, também fixas, dadas a priori, restando ao pesquisador, buscar, captar, apropriar-se e, por conseguinte, descrever e retratar o que "está dado".

Todas estas perspectivas, portanto, apresentam uma concepção de história como se estivesse desprovida de contradições. Entende-se como se não tivesse movimento, nem direção. Deste modo, temos uma concepção de história factual, fixa ou, no máximo, conduzida por um desenvolvimento natural. São concepções que efetivamente não correspondem à realidade. Noutras palavras, pode-se afirmar que, contraditoriamente, são concepções de história a-históricas, que não permitem compreender os fenômenos na sua integralidade e na sua totalidade.

Nesta perspectiva, por um lodo, conceitos como totalidade, classes sociais, antagonismos sociais, conflitos de classes, contradições, universalidade e Estado, deixam de ser considerados na análise das fontes. Por outro, a verdade, ou se entende como sendo evidente em si, já que os dados, os objetos, as fontes "estão aî" e "falam por si", em função da supervalorização do empírico ou, devido à exaltação do subjetivo e do imaginário, confunde-se a verdade com aquilo que o "sujeito" atribui aos objetos ou com o que é idealizado por ele. Em decorrência disso, temos uma concepção de história fragmentada, difusa, dispersa, relativista. Ao contrário disso, defendemos uma perspectiva metodológica que revele o particular na sua relação com o universal, com a totalidade das relações sócioeconômicas, políticas e culturais de determinada época e sociedade, dialeticamente articuladas.

\section{História, arquivos e fontes na pesquisa em História da Educação}

Como dissemos, as fontes são os meios pelos quais podemos acessar o passado, que pode ser mais recente ou distante, conforme for o caso. Contudo, como não podemos ter acesso a ele diretamente, restam-nos as fontes que permitem e fazem a mediação. Assim, pesquisar sobre elas significa retornar ao passado. Ou seja, promover um percurso ou caminho inverso ao da produção dos fatos e da história. Mas, o que são fontes?

Fontes são documentos, registros, marcas, vestígios, deixados por indivíduos, por grupos, pelas sociedades, pela natureza, que representam ou expressam uma determinada forma de ser da matéria, quer seja ela natural, humana ou social, em seu processo de contradição e transformação. $\mathrm{O}$ acesso a elas, torna-se um meio de conhecer o passado, permite desvendar os hábitos, os costumes, a produção, a distribuição e o consumo, a forma de organização de indivíduos e das sociedades, conhecer o modo de sobrevivência.

Ao contrário do que os positivistas afirmam, porém, as fontes não falam por si. Elas são uma "construção do pesquisador". A partir da existência e localização do(s) objeto(s), 
mediados pelos conhecimentos, instrumentos e meios de cada momento, o pesquisador "produz as fontes" enquanto sentido com o intuito de conhecer um determinado momento, uma sociedade e ou relações. Pela leitura, análise, ação e interpretação, o pesquisador "revela" as fontes, produz conhecimento histórico. Contudo, o fato de as fontes serem uma recriação, não significa que o pesquisador as cria do nada, não são produtos de mentes brilhantes, não são uma invenção do agente, nem uma recriação literal, absoluta, tais quais foram exatamente. Com Karl Marx poderíamos dizer que o pensamento é o instrumento pelo qual o pensamento se utiliza para buscar compreender os fenômenos, sem confundir o real com o ideal, nem este com aquele.

Como afirma Ragazzini (apud ORSO, 2004, p.2),

a fonte é uma construção do pesquisador, isto é, um reconhecimento que se constitui em uma denominação e em uma atribuição de sentido; é uma parte da operação historiográfica. Por outro lado, a fonte é o único contato possível com o passado que permite formas de verificação. Está inscrita em uma operação teórica produzida no presente, relacionada a projetos interpretativos que visam confirmar, contestar ou aprofundar o conhecimento histórico acumulado. A fonte provém do passado, é o passado, mas não está mais no passado quando é interrogada. A fonte é uma ponte, um veículo, uma testemunha, um lugar de verificação, um elemento capaz de propiciar conhecimentos acertados sobre o passado.

Todavia, como a história é história justamente devido ao processo de transformação, isso implica que muitas das fontes também acabaram por se "perder", transformar-se, tornando difícil recuperar, desvendar, desvelar e "recriar" fielmente o passado. Daí a contradição, pois, por um lado, só há história porque há transformação. Entretanto, a transformação implica em deixar de ser fonte, ao menos como existiu no passado, ou que a fonte, apareça de outra forma. Ter presente isso, por um lado, faz com que não extraiamos conclusões apressadas, que tomemos um objeto, um vestígio, um documento e concluamos imediatamente que a realidade era isso ou aquilo. Ou seja, é necessário que o pesquisador tenha cuidado e seriedade tanto no trato com as fontes e com a história, como com o método de pesquisa a ser adotado. É próprio da história a transformação. Entretanto, tendo presente isso, também precisamos considerar que isso pode implicar na impossibilidade de "recuperar" o passado.

Uma vez que a história tem a ver com transformação, ainda que possamos dizer que na natureza também ocorrem transformações, para diferenciar as transformações que nela ocorrem, das produzidas com ou sob a interferência do homem, tomamos como sinônimo de história, a história humana e social, ou seja, aquela que se ocupa das transformações ocorridas a partir da influência ou interferência do homem.

É neste sentido que podemos falar de fontes históricas, que são aquelas que dizem respeito aos vestígios, aos documentos, objetos, instituições ou relações que estão articuladas às atividades, às ações, ao processo de transformação desencadeados pelos homens em determinada época e local do passado. Assim, tanto podem ser fontes históricas, um pedaço de carvão, uma pedra polida, uma ponta de lança, um resto de utensílio, um pedaço de osso, uma arte rupestre, como também os registros escritos, as crônicas, as cartas, as obras literárias, os diários, os jornais velhos, as fotos, as marcas de uma construção, os tipos de habitação, os monumentos, um caderno, uma lousa, um pergaminho, uma máquina de escrever, um lápis, um computador ou uma determinada tecnologia, enfim, poderíamos enumerar um infindável número de tipos de fontes das mais diversas possíveis. 
Os arquivos, por sua vez, são um segundo momento do processo de pesquisa. A partir do momento em que as fontes são localizadas e selecionadas, advém o processo de catalogação, de registro, organização de arquivos para possibilitar melhor preservação das mesmas e ampliar a memória histórica. Neste sentido, os arquivos são fundamentais para preservação das fontes, o que equivale a dizer, para preservação da própria histórica.

Os arquivos se constituem em conjuntos de documentos produzidos ou recebidos por órgãos públicos, instituições de caráter público e entidades privadas, em decorrência do exercício de atividades específicas, bem como pessoa física, qualquer que seja o suporte da informação ou a natureza dos documentos (MEDEIROS, 2003, p.1).

$\mathrm{Na}$ atualidade, cada vez mais se faz uso dos acervos catalográficos, das bibliotecas e dos museus, públicos e/ou particulares, como forma de dar uma sobrevida às fontes históricas.

Tanto as fontes individuais, quanto as coleções de fontes, os arquivos, não são meros objetos. São objetos que expressam as mudanças pelas quais a vida do homem foi passando ao longo do tempo. Portanto, elas dizem respeito à sua sobrevivência. Como afirmam Marx e Engels, em A Ideologia Alemã,

Contrário aos alemães, que não dispõem de quaisquer pressupostos, somos forçados a começar por constatar que a primeira premissa de toda a existência e, portanto, também de toda a história, ou seja, a premissa de que os homens têm de estar em condições de viver para poder fazer história. Mas, da vida fazem parte sobretudo comer, beber, habitação, vestuário e ainda algumas outras coisas mais. O primeiro ato histórico é, portanto, a produção dos meios para a satisfação destas necessidades, a produção da própria vida material, e a verdade é que este é um ato histórico, uma condição fundamental de toda a história, que ainda hoje, tal como há milhares de anos, tem de ser realizado dia a dia, hora a hora, só para manter os homens vivos (1981, p. 36-37). (nosso itálico)

Dito de forma diferente, a existência de fontes históricas e de arquivos ou acervos, supõem a existência do homem. É em decorrência do fato de o homem existir que surgiram as fontes. Ou seja, em função da produção da existência do homem, também se produzem as fontes, apesar delas não se referirem exclusivamente às produções humanas.

Como afirmam os autores, não é possível se fazer história se o homem não estiver vivo. Mas, para viver é preciso comer, beber, habitar, vestir e algumas (infinitas) coisas mais. Para isso, é preciso transformar a natureza, o meio e se transformar. Portanto, é na relação do homem com o meio e no processo de produção das coisas necessárias à sobrevivência que se produzem as fontes. Neste sentido, qualquer que seja a fonte, sempre diz respeito à história do homem.

Bem entendido, então, pode-se afirmar que as fontes dizem respeito à vida do homem. E o acesso a elas, todavia, então, não representa apenas o acesso a meros objetos, mas sim, objetos que expressam e revelam uma forma de ser, produzir, organizar-se e viver socialmente. É com essa finalidade que devemos pesquisar, levantar, catalogar e preservar fontes. Então, preservar fontes, significa preservar a própria história do homem, que nada mais é do que o seu processo de transformação ao longo do tempo, sua relações, sua forma de ser.

Aqui é importante fazermos algumas distinções sobre a questão do passado. Uma vez que não mais temos acesso à história diretamente, pois, não mais estamos vivendo na 
imediaticidade dos fatos, precisamos distinguir a história propriamente dita e vivida, da história dita, escrita, revelada e ainda da disciplina de história. Apesar de terem algo em comum, cada uma tem lá suas especificidades.

A primeira diz respeito ao vivido, experienciado diretamente pelo homem, no momento da ocorrência dos fatos. A segunda, diz respeito a aquilo que, mediado pelos conhecimentos, pelas condições e instrumentos de cada momento, o pesquisador consegue se apropriar, recriar e traduzir na forma de ideias, representações e teorias o que foi vivido realmente, o que de fato aconteceu. A terceira refere-se a aquilo que se ensina na disciplina de história, que é uma síntese da história vivida, porém, mediada pelos pesquisadores e apresentada sob determinada perspectiva como sendo a história real.

Não se pode confundir nenhuma delas, da mesma forma que não se pode entender como se as três fossem uma coisa só. Há uma distância entre a história vivida, aquilo que é apreendido pelos pesquisadores e aquilo que finalmente acaba sendo sintetizado, filtrado e produzido para os alunos, de acordo com a concepção ideológica, com a posição política e econômica do pesquisador/historiador.

Não podemos nos esquecer, portanto, de que as ideias, as teorias e o conhecimento não são neutros. Portanto, é preciso considerar a posição e o lugar social de onde são feitas a análises e interpretações acerca das fontes. Assim, ao se analisar a história, os arquivos, as instituições e fontes na pesquisa e na história da educação, não se deve olvidar de que cada perspectiva de análise parte de determinados pressupostos e também tem em vista determinados fins. Por isso, não se pode pensar que se trata da pura objetividade, até mesmo porque é uma construção, e, como tal, tem a ver com as posições, compreensões, ideologias e compromissos sociais dos pesquisadores.

\section{Referências}

HOBSBAWM, Eric. Sobre História. São Paulo: Companhia da Letras, 1998.

LOMBARDI, José Claudinei. História e Historiografia da Educação: atentando para as fontes. In: LOMBARDI, José Claudinei [at al]. Fontes, História e Historiografia da Educação. Campinas, SP: Autores Associados: HISTEDBR; Curitiba, PR: Pontifícia Universidade Católica do Paraná (PUCPR); Palmas, PR: Centr4o Universitário Diocesano do Sudoeste do Paraná (UNICX); Ponta Grossa, PR: Universidade Estadual de Ponta Grossa (UEPG), 2004 - Coleção Memória da Educação).

MARX, K e ENGELS, F. Ideologia Alemã. São Paulo: 1981, p. 36-37

MEDEIROS, Ruy. Arquivos escolares: breve introdução a seu conhecimento. In: Simpósio do Museu Pedagógico, 3, 2003, Bahia. Disponível em: <http://www.histedbr.fae.unicamp.br >. Acesso em: 29 jul. 2005.

MIGUEL, Maria Elisabeth Blanck. Do levantamento de fontes à construção da historiografia: uma tentativa de sistematização. In: LOMBARDI, José Claudinei [at al]. Fontes, História e Historiografia da Educação. Campinas, SP: Autores Associados: HISTEDBR; Curitiba, PR: Pontifícia Universidade Católica do Paraná (PUCPR); Palmas, PR: Centr4o Universitário Diocesano do Sudoeste do Paraná (UNICX); Ponta Grossa, PR: Universidade Estadual de Ponta Grossa (UEPG), 2004 - Coleção Memória da Educação).2004.

NOSELLA Paolo e BUFFA, Ester. As Pesquisas sobre instituições escolares: um balanço. 
http://www.faced.ufu.br/colubhe06/anais/arquivos/463PaoloNosella_EsterBuffa.pdf. Consultado em 20.08.11.

ORSO, Paulino et. al. A importância do levantamento e da catalogação de fontes para a história da educação brasileira: um relato preliminar do trabalho realizado em Cascavel PR. In.: Anais da IV Jornada do HISTEDBR - História Sociedade e Educação no Brasil: História e historiografia da educação. Ponta Grossa: UEPG, 2004.

PINTO, Alvaro Vieira. Ciência e existência. Rio de Janeiro: Paz e Terra, 1979.

Notas

${ }^{1}$ Artigo resultante da Conferência proferida no I ${ }^{\circ}$ Colóquio de Pesquisa: Arquivos, Instituições Escolares e Memória Histórica, realizado na Unioeste, no dia 30 de agosto de 2011, organizado pelo Grupo de Pesquisa em História, Sociedade e Educação no Brasil - GT da Região Oeste do Paraná - HISTEDOPR.

2 Doutorado em História e Filosofia da Educação pela Unicamp, docente dos Cursos de Pedagogia e Mestrado em Educação da Unioeste e líder do Grupo de Pesquisa HISTEDOPR/UNIOESTE/ Campus Cascavel

${ }^{3}$ É importante esclarecer que esta discussão sobre História, arquivos e fontes na pesquisa em História da Educação, tem a ver com a história de nosso grupo de pesquisa, o - HISTEDOPR - do Grupo de Pesquisa em História, Sociedade e Educação no Brasil - GT da Região Oeste do Paraná, que foi criado em 2002, em Cascavel, no Oeste do Paraná, e reestruturado em 2003, quando retornei do doutorado e fui convidado pelos professores João Carlos da Silva e André Paulo Castanha para assumir a liderança do mesmo. Inicialmente, fiquei um tanto em dúvida e relutante, mas acabei assumindo o desafio. Porém, a partir daí retomei o trabalho de organização do grupo, elaboramos nosso regimento e definimos as prioridades. O grupo está vinculado ao HISTEDBR, que é um grupo nacional, criado em 1986, sob a liderança do Prof. Dermeval Saviani. Atualmente, é composto por cerca de 30 GTs (grupos de trabalho) espalhados pelo Brasil a fora, unidos em torno de um objetivo comum, realizar pesquisas, catalogar, preservar e socializar Fontes Primárias e Secundárias para a História da Educação Brasileira, de tal modo que não só possibilite um conhecimento mais aprofundado sobre a História da Educação do Paraná, como também contribuir para melhor conhecer a história Brasil. No Paraná, o HISTEDBR conta com 6 Grupos: Maringá, Londrina, Ponta Grossa, União da Vitória, Curitiba e Cascavel. No âmbito da pesquisa, nos colocamos um desafio coletivo (promover o Levantamento e a Catalogação de Fontes em História da Educação na Região Oeste do Paraná), no qual todos os integrantes do grupo estão envolvidos. Dentro dele articulam-se diversos subprojetos: Levantamento e Catalogação de fontes, História Regional, História da Escola Pública, questões teórico-metodológicas, epistemologia e ensino de história, dentre outras. Além destas pesquisas, cada um dos integrantes do grupo desenvolve pesquisas individuais, de acordo com sua área de atuação, com seus interesses. Desta forma pretendemos contribuir com os demais grupos que integram o HISTEDBR, para ampliar o levantamento, a organização, a catalogação e preservação das fontes em âmbito nacional.

${ }^{4}$ Para aprofundar as discussões em torno desta questão indicamos: As pesquisas sobre instituições escolares: balanço crítico, de autoria de Paolo Nosella e Ester Buffa.

http://www.faced.ufu.br/colubhe06/anais/arquivos/463PaoloNosella_EsterBuffa.pdf. Consultado em 20.08 .11 .

Recebido em: $\quad 09.05 .12$

Aprovado em: $\quad 30.05 .12$ 